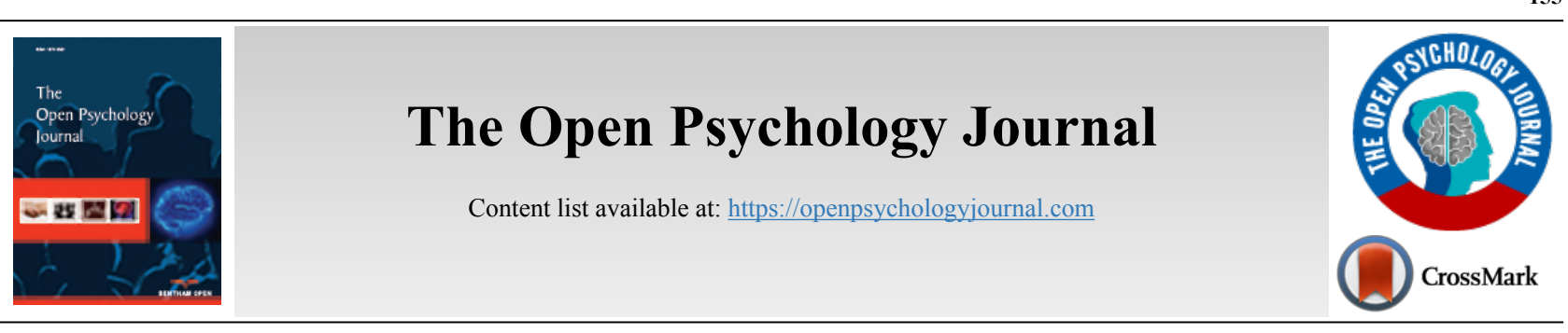

RESEARCH ARTICLE

\title{
Low Self-Esteem and Selfie Posting Among Young Women
}

\author{
Roberta Biolcati ${ }^{1, *}$ \\ ${ }^{\prime}$ Department of Education Sciences, University of Bologna, Bologna, Italy
}

\begin{abstract}
:
Background:

Self-esteem is a critical factor in online impression management strategies and could play a crucial role in explaining women's selfie-posting behaviours. Previous works examining relationships between self-esteem and self-presentation on social media have yielded controversial results.

Objective:

This study was performed to clarify the relationship between self-esteem and the frequency of taking and posting own, group and partner selfies on Social Networking Sites (SNS).

Methods:

A sample of 692 Italian young women (18-28 years old) completed questionnaires on self-esteem, satisfaction with life, body satisfaction and selfie posting bahaviours. The low self-esteem group was compared with the high self-esteem group.

Results:

Results showed that women with low self-esteem are more dissatisfied with their body image and life and significantly they post fewer types of selfies compared to women with high self-esteem.

Conclusion:

Findings from this study provide new insights into the relation between self-esteem and selfie impression management strategies.
\end{abstract}

Keywords: Self esteem, Selfie posting, Body image, Women's self presntation, Social media, Self presentation.

\begin{tabular}{|l|l|l|r} 
Article History & Received: March 06, 2019 & Revised: June 25, 2019 & Accepted: August 20, 2019
\end{tabular}

\section{INTRODUCTION}

Self-esteem is a part of the psychological representation of individuals [1] and is the emotional evaluation of the person's own worth, that is, the individual's judgment of him/herself [2]. A large number of cross-cultural studies have provided strong evidence that across samples, and measures, women tend to have lower self-esteem than men [3]. A wide range of literature also yields evidence of a close association between self-esteem and body image satisfaction [4], especially amongst young women [5]. Specifically, body image is consi-dered to be the 'mental portrait' that individuals form of their physical selves [6]. In recent years, one's own online body image display has come widely into use due to the spread of Social Networking Services (SNS) such as Instagram or Face-

\footnotetext{
"Address correspondence to this author at the Department of Education Sciences,
} University of Bologna, via Filippo Re 6, Italy; E-mail: r.biolcati@unibo.it book. Online body display is the definition of one's own body exhibited in an online public platform of free access [7]. In particular, selfies, defined as a self-portrait taken with a handheld smartphone or camera [8 - 10], are being posted on social media every day and are becoming popular especially among young adults. In general, young people (aged 18-29 years) are the highest SNS users [11] and selfies are prevalent at this stage of life: a report found that $96 \%$ of young adults (aged 20-23 years) had taken a selfie some time in the past, and $25 \%$ had taken a selfie the previous day [12]. Regarding the frequency of selfie posting behaviour, research has shown that in general, young women take and post more selfies on social media as compared to men [13].

The present study aims to investigate, in a large sample of young women, SNS users, self-esteem (the psychological portrait) and its relationship with other self-related constructs such as body satisfaction (a mental portrait of the physical self) 
and the selfie (the self-portrait taken and posted on social media).

\subsection{Selfies and Self-Esteem: Mixed Results}

Several studies have shown a beneficial effect of selfies on self-esteem thanks to the possibility of selective selfpresentation on social media, such as editing one's own SNS profile [14]. In fact, SNS provide an ideal platform for individuals to present themselves as they would like to be seen by others [15]. Scholars [16] have argued that SNS users are prone to sharing photos of themselves for self-promotional purposes, including preserving a positive self-image. Generally, online-self presentation via SNS is much more controlled than self-presentation in offline spaces, since the former can be edited and rearranged before posting, with countless opportunities to manage the image perceived by others [17]. For this reason, selfie posting behaviours appear as a new phenomenon with the high potential for self-presentation and impression management: by definition, selfies are focused on the self convey of emotions and an image as desired to provide the best opportunities for a strategic self-presentation $[18,19]$.

Pounders and colleagues [20] showed that impression management is a core issue in understanding why women post selfies, and in particular, self-esteem could play a crucial role in explaining their selfie-posting behaviour. Indeed, selfies typically focus on users' physical appearance and women of Western culture have internalized the culturally dominant ideals of attractiveness and self-evaluation based on aesthetic appearance. Scholars [21] argued that women living in sociocultural environments that insistently and pervasively engender pressure for the "ideal" physical appearance are more likely to engage in behaviours of image impression management, such as selfies, that confirm the sense of connection between their physical bodies and their sense of self-worth. Furthermore, the global economic crisis that began in 2008, whose effects are still ongoing in some countries like Italy, may have a very important impact on people's values, self-confidence and self-esteem. Indeed, studies suggest that various well-being indicators, such as self-esteem and life satisfaction, are negatively affected by economic recessions [22]. Specifically for young people, evidence from Europe and the United States suggests that in recession periods, feelings of selfworth have eroded [23]. This can have repercussions on young womens' self-esteem by increasing the importance ascribed to the self-image for their wellbeing. In this scenario, selfie posting behaviours could be considered as an expression of the need for self-esteem regulation [24]. For instance, women post selfies to enhance their self-esteem, which may occur through the number of "likes" the selfie receives [20].

Although some studies reported that self-esteem may be strongly linked to the need for self-presentation on SNS [25], the results to explain this association are controversial.

On one hand, Mehdizadeh [26] noted that individuals with low self-esteem engaged in more self-promoting behaviours on Facebook than individuals with higher self-esteem, and in particular, women characterized by low self-esteem posted more self-promoting photos online than women with higher self-esteem [27]. Individuals with lower levels of self-esteem reported posting more selfies on social media [9] and young adult women who are low in self-esteem turn to social media to satisfy gratifications, such as validation regarding physical and social attractiveness, fostered by the online environment [28].

On the other hand, individuals with higher self-esteem tend to be more extrovert, agreeable, conscientious, emotionally stable, and more open to experience [29]. Self-esteem may also be associated with popularity in an online environment such as Instagram or Facebook. Individuals with high self-esteem are more satisfied with their body image and are more often selfemployed, and self-confident, than those with low self-esteem [30]. Indeed, people with high self-esteem think they are already acceptable and want to enhance an already higher status. Consistent with this theoretical line, some authors have reported that women's self-esteem is positively related to selfie-posting [31].

In sum, we start from conflicting results regarding selfesteem and selfie posting behaviours. This controversy can be explained within the broader competing hypotheses proposed by Valkenburg and Peter [32]: The Social Compensation ("Poor Get Richer") hypothesis, that those who perceive their offline social networks to be inadequate compensate for them with more extensive online social networks use. The other hypothesis is the Social Enhancement "Rich Get Richer" suggesting that those with more developed offline social networks enhance them with more extensive online social networks use. Following this theoretical framework, as far as self-esteem is concerned, through the use of selfies low selfesteem women want to compensate their deficiencies in order to be acceptable and high self-esteem women think they are already pleasing and want to enhance their social capital [33].

Therefore, given the conflicting results between studies, the centrality of self-esteem for women and online body image display, the current research aims to explore the relationship between self-esteem and the frequency of selfie posting behaviours on SNS within the young female population. Specifically, we expect women with lower self-esteem to be more dissatisfied with their body and with life, in general, than those with higher self-esteem, and we want to explore the differences in selfie posting frequencies between low $v$ sigh self-esteem groups.

\section{METHODS}

\subsection{Procedure}

Participants were recruited online, using an online questionnaire built with Google Forms, a survey-generating tool. The sample was contacted via the Internet, and participants were asked to answer some questions on self, body image and selfie posting behaviours. In detail, the questionnaire was publicly accessible and an invitation with the link to the tool was disseminated to the potential participants by means of three systems: mailing lists, a newsgroup of university undergraduate students, and via popular social networking sites, such as Facebook and Instagram. No personal identifying information was collected. In order to check and prevent a person re-entering the survey site, the subject's IP address was monitored. As standard procedure for minimal-risk online surveys, the study waived documentation of informed consent, by permitting continued participation to signal 
consent. Thus the informed consent of the participants was implied through survey completion. No fee was offered. The data were collected in 2018. The study was conducted in agreement with the ethical norms set by the Italian National Psychological Association. An additional ethical approval was not required since no treatment was involved, including invasive diagnostics or procedures causing psychological or social discomfort for the participants.

\subsection{Participants}

A total of 692 young women coming from the North (36\%, $\mathrm{n}=249)$, Centre $(27.7 \%, \mathrm{n}=192)$ and South $(36.3 \%, \mathrm{n}=251)$ of Italy participated in the survey. All the participants stated that they have a personal profile on SNS, such as Facebook, Instagram, Twitter or Myspace. Their age ranged between 18 and 28 years $(\mathrm{M}=23.40, \mathrm{SD}=2.33)$. Two hundred and ninetyone participants $(42.1 \%)$ attended the $1^{\text {st }}$ Cycle Degree, 223 (32.2\%) attended the $2^{\text {nd }}$ Cycle Degree, while 178 (25.7\%) did not attend university. With regard to their current relational status, $410(59.2 \%)$ had a partner, $266(38.4 \%)$ were single and $16(2.3 \%)$ were married.

\subsection{Tools}

The questionnaire included a first section regarding age, relational status, education level, and region of provenance. A dichotomously posed question (yes/no) inquired as to whether the participant had a profile on a social network site. The few people who answered negatively were removed from the sample.

We asked the participants about their satisfaction level (five-point Likert scale from "not satisfied at all" to "fully satisfied") with four areas in school performance, relationships with friends, relationships with the partner and relationship with the family of origin. The four items, specifically readapted by the authors for the purpose of the study, were sourced from a previous study [34]. The scale has not yet been validated.

\subsubsection{Self-Esteem}

The most popular tool for measuring self-esteem is the Rosenberg Self Esteem Scale [35] (RSES). The RSE scale is a 10 -item instrument in which participants respond to each item on a 5 -point Likert-scale (from $1=$ strongly disagree to $5=$ strongly agree). Example items include: "On the whole, I am satisfied with myself" and "All in all, I am inclined to feel that I am a failure" (reversed item). An RSE index was computed as the mean of all the items $(\alpha=.89)$, so that higher totals reflect higher self-esteem.

\subsubsection{Body Satisfaction}

Body satisfaction was assessed using one of the four subscales of the validated Body Investment Scale [36] (BIS), namely 'body attitudes/feelings'. This scale evaluates feelings of love and approval towards the body with items such as 'I am satisfied with my appearance' (reversed) and 'I feel anger toward my body'. It consists of six items assessed on a score ranging from 1 ('Do not agree at all') to 5 ('strongly agree'). In this study, the internal consistency (Cronbach's alpha) of the resulting BD scale scores was $\alpha=.92$.

\subsubsection{Selfie-Posting Behaviours}

Overall, the selfie-posting frequency was measured using one item on a Likert scale (from $1=$ never to $6=$ always): "How often would you say that you take and post selfies on SNSs?" Participants also specified the frequency with which over the past 30 days they had posted on social networks (from $1=$ never to 6 = always): own selfies; group selfies; selfies with the partner. The single items about selfie frequencies are based on a previous study on selfie posting behaviours [8].

\subsection{Analytical Procedures}

First, the frequencies and means were computed for each variable. Second, the statistical artifice of splitting participants into groups based on the average scores on the Likert-scale questionnaire (i.e.. RSES), using the lowest quartile, allowed to isolate participants with the lowest level of self-esteem that qualitatively differ from others. Third, chi-square and analysis of variance (one-way ANOVA) were used to evaluate differences between the low-self-esteem group vs. high-self esteem group among the study variables.

\section{RESULTS}

The Rosemberg Self Esteem Scale foresees a minimum score of 10 and a maximum of 50. Among the young women examined, the minimum score was 10 , while the maximum was 45. The mean score was $33.91(\mathrm{SD}=7.19)$. We split the sample at the bottom $25 \%$ (the lowest quartile): the group that scored from 10 to 29 was named "Low Self-Esteem" (LSE) $(27.2 \%, \mathrm{n}=188)$ and the group scored from 30 to 45 as "High Self-Esteem" (HSE) $(72.8 \%, \mathrm{n}=504)$. The LSE group was then compared with the HSE group. With regard to personal data, there is no significant difference between the two groups with respect to the region of provenience. Considering the level of education, Chi-square test showed that in the LSE group, there were more women attending the 1 st Cycle Degree than in the other group $\left(42.6 \%\right.$ vs $\left.27.8 \%, \mathrm{x}^{2}=16.60 . \mathrm{df}=3 ; \mathrm{p}=0.001\right)$. With regard to the relational status, a higher percentage of single women is represented in the LSE group $(48.9 \%$ vs $34.5 \% \mathrm{x}^{2}=12.14$, df $=2$; p. $=0.002$ ).

In general, as can be seen in Table 1 (left part), descriptive statistics showed that participants have a high average of life satisfaction and a medium-high level of body satisfaction. In the overall sample, the young women declared they did not post own, group or partner selfies very frequently.

ANOVA analysis ${ }^{1}$, (Table 1) showed that the women with low self-esteem are younger $\left(M_{\mathrm{LSE}}=22.74 v\right.$ s. $M_{\mathrm{HSE}}=23.64 ; F$ $(1,687)=20.72 ; p=.000)$ and have a significantly lower satisfaction level average in all the four areas of life than the high self-esteem women: school performance $\left(M_{L S E}=3.31 \mathrm{vs}\right.$. $\left.M_{H S E}=3.39 ; F(1,691)=61.79 ; p=.000\right)$, relationships with friends $\left(M_{L S E}=2.95\right.$ vs. $M_{H S E}=3.84 ; F(1,691)=118.62 ; \mathrm{p}=$ $.000)$, relationships with the partner $\left(M_{L S E}=2.84 v s . M_{H S E}=\right.$ $3.63 ; F(1,691)=48.85 ; p=.000)$ and relationship with the family $\left(M_{L S E}=3.47\right.$ vs. $M_{H S E}=4.09 ; F(1,691)=47.66 ; p=$ $.000)$ In addition, the former have a lower body satisfaction than the latter $\left(M_{L S E}=15.44\right.$ vs. $M_{\mathrm{HSE}}=22.33 ; F(1,691)=$ 218.54; $p=.000)$.

\footnotetext{
${ }^{1}$ The missing data do not exceed $0.6 \%$ and have not been taken into account in the analyses.
} 
Table 1. Significant differences between Low Self-Esteem and High Self-esteem groups on Age, Live Satisfaction, Body Satisfaction and Selfie posting frequencies

\begin{tabular}{|c|c|c|c|c|c|}
\hline \multirow[b]{2}{*}{ Measures } & \multirow[b]{2}{*}{$M$} & \multirow[b]{2}{*}{$S D$} & \multicolumn{2}{|c|}{ Self-Esteem } & \multirow[b]{2}{*}{$\boldsymbol{F}$} \\
\hline & & & $\begin{array}{c}\text { M Low } \\
(N=188)\end{array}$ & $\begin{array}{c}\text { M High } \\
(N=504)\end{array}$ & \\
\hline Age & 23.40 & 2.33 & 22.74 & 23.64 & $20.72 * * *$ \\
\hline \multicolumn{6}{|l|}{ Satisfaction Level $(1,5)$} \\
\hline School performance & 3.75 & .95 & 3.31 & 3.39 & $61.79 * * *$ \\
\hline Relationships with friends & 3.59 & 1.03 & 2.95 & 3.84 & $118.62 * * *$ \\
\hline Sentimental relationships & 3.42 & 1.38 & 2.84 & 3.63 & $48.85 * * *$ \\
\hline Relationship with the family & 3.92 & 1.07 & 3.47 & 4.09 & $47.66^{* * *}$ \\
\hline Body Satisfaction $(5,30)$ & 20.46 & 6.25 & 15.44 & 22.33 & $218.54 * * *$ \\
\hline All Selfie Frequencies $(1,6)$ & 2.94 & .98 & 2.76 & 3.01 & $8.73 * *$ \\
\hline Own Selfie $(1,6)$ & 2.01 & 1.22 & 1.81 & 2.08 & $6.80^{* *}$ \\
\hline Group Selfie $(1,6)$ & 2.16 & 1.25 & 1.96 & 2.24 & $7.19^{* *}$ \\
\hline Partner Selfie $(1,6)$ & 1.75 & 1.25 & 1.47 & 1.85 & $12.64 * * *$ \\
\hline
\end{tabular}

With regard to differences in selfie posting frequency, the LSE group significantly post fewer all types of selfies $\left(M_{\mathrm{LSE}}=\right.$ 2.76 vs. $\left.M_{\mathrm{HSE}}=3.01 ; F(1,691)=8.73 ; p=.003\right)$, own selfies $\left(M_{\mathrm{LSE}}=1.81\right.$ vs. $\left.M_{\mathrm{HSE}}=2.08 ; F(1,691)=6.80 ; p=.009\right)$, group selfies $\left(M_{\mathrm{LSE}}=1.96 v s . M_{\mathrm{HSE}}=2.24 ; F(1,691)=7.19 ; p\right.$ $=.007)$ and partner selfies $\left(M_{\mathrm{LSE}}=1.47\right.$ vs. $M_{\mathrm{HSE}}=1.85 F(1$, $691)=12.64 ; p=.000)$, compared to the HSE group.

\section{DISCUSSION}

Self-esteem was identified as a critical factor in SNS users' online impression management strategies [20]. Specifically, selfie-postings via social media have become a very common form of young women's "controlled" self-presentation. Previous works examining relationships between self-esteem and self-presentation on social media, namely selfie posting behaviour, have yielded mixed and controversial results [26, 37] and further investigation is needed [38]. This study aimed to contribute to the literature on young women's online behaviour by comparing women with low self-esteem to women with higher self-esteem in regard to selfie posting behaviours.

Our findings revealed that women with the lowest selfesteem posted fewer own, group and partner selfies than others. Women who have the lowest self-esteem tend to be younger, without an effective relationship and they had posted fewer selfies of all types in the last 30 days. As expected, they were more body dissatisfied and less happy with all aspects of their life. Their general unhappiness and lack of appreciation for their body image probably lead them to have no confidence in the impression management strategy provided by the selfies.

These findings disagree with those reported by Krämer and Winter [39] arguing that people with low self-esteem might be even more willing to engage in online self-promotion in order to raise their self-esteem.

In agreement with Sorokowska and colleagues [38], who, as in this study, focused on a sample of only women, we noted that only medium-high self-esteem is positively related to selfie-posting frequencies. Our findings support previous studies that reported online self-presentation to be positively linked with individuals' self-esteem [40]. Women have learned to believe that physical appearance is an important source for self-evaluation [41, 42]. Thus, when women post selfies, they take pride in their own body image and evaluate themselves positively [43, 44]. Following Ridgway and Clayton [7], we think that if women are satisfied with their overall body image, self-promotion of their body satisfaction may take the form of online behaviours, specifically selfie posting behaviours. Therefore, with regard to the relationship between self-esteem and selfies, the results support the hypothesis of Social Enhancement [32], according to which those who have fair or great confidence in themselves post more selfies in an attempt to further increase their image.

Conversely, women with low self-esteem tend to protect themselves against the shame and loss of face that might result from social comparison or social disclosure [45]. Low selfesteem has been widely linked to depression, social anxiety, body dissatisfaction and general unhappiness [46]. Although social media offers people the chance to impress without vis a vis embarrassment or the fear of being rejected, women with low self-esteem do not seem to be drawn to appearing on social networks via selfies. In line with Alblooshi [47], the study shows that people with lower self-esteem may be taking and posting fewer selfies because they are less comfortable with their appearance.

Furthermore, selfies contribute to forming a personal diary and are a way to share emotions with a partner, friends and family: individuals with low self-esteem are in general less satisfied with their relationships and with sharing opportunities. Indeed, it is more likely that they tend to be self-protective, trying to prevent or lessen any social disapproval [28]. In sum, it may be that women with low self-esteem will participate in SNS in a non-self-enhancing manner, namely settling for the extravagance of gleaning information about other people without having to reveal anything about themselves. People with low self-esteem may, in fact, be more prone than others to becoming so-called "lurkers," namely people who browse social media to see images of others without self-disclosure 
[48]. The risk of lurking for women with low self-esteem may activate discrepancies between themselves and social standards, and consequently further lower self-esteem [49]. Additional studies should investigate this hypothesis.

This exploratory study has several limitations. In particular, the statistical artifice of division into groups and the cross-sectional design may have provided biased results. Future studies must look more deeply into the causal relationship between the variables. Moreover, the results are limited to claimed selfie posting frequencies and the study used single items that have not been validated to measure selfie posting. Therefore, there is a need for future studies to structure and validate a selfie posting behaviour scale. In addition, the authors suggest that future research will need to incorporate tools that actually reflect the time spent on 'lurking' in social media and in viewing other people's selfies.

Although the present study was interested in studying selfie posting behaviours among young women, extending the study to other ages and cultures could be of considerable interest and it might increase the generalizability of the results.

In any case, the preliminary findings provide additional insight into the relationship between women's self-esteem and selfie impression management strategies. In particular, the results suggesting that young women with low self-esteem post fewer selfies provide evidence that should allay society's concerns [50] over the harmful consequence of excessive selfie postings for the most psychologically sensitive individuals. The study suggests that taking selfies is a strategy used mostly by women who are more self-confident and claim to be happier in life in general.

\section{CONCLUSION}

Finally, this exploratory research may have practical implications, since selfie-posting behaviour has become a widespread phenomenon in the lives of many people: a closer examination of the relationship between self-esteem and selfies may be helpful to differentiate normative vs. pathological social networking activities. For instance, selfie-posting behaviours can have a potentially negative impact on selfesteem for those who cannot benefit from them and are exposed passively to their viewing.

\section{ETHICS APPROVAL AND CONSENT TO PARTICIPATE}

The study was conducted in agreement with the ethical norms set by the Italian National Psychological Association.

\section{HUMAN AND ANIMAL RIGHTS}

No animal/human was used for studies as the basis of research.

\section{CONSENT FOR PUBLICATION}

Not applicable.

\section{AVAILABILITY OF DATA AND MATERIALS}

Not applicable.

\section{FUNDING}

None.

\section{CONFLICT OF INTEREST}

The author declares no conflict of interest, financial or otherwise.

\section{ACKNOWLEDGEMENTS}

The author would like to thank Alessandra Passeri for helping in the data collection.

\section{REFERENCES}

[1] Marsh H. A multidimensional, hierarchical model of self-concept: Theoretical and empirical justification. Educ Psychol Rev 1990; 2(2): 77-172.

[http://dx.doi.org/10.1007/BF01322177]

[2] Biolcati R. The role of self-esteem and Fear of negative evaluation in compulsive buying. Front Psychiatry 2017; 8: 74. [http://dx.doi.org/10.3389/fpsyt.2017.00074] [PMID: 28512435]

[3] Bleidorn W, Arslan RC, Denissen JJ, et al. Age and gender differences in self-esteem-A cross-cultural window. J Pers Soc Psychol 2016; 111(3): 396-410.

[http://dx.doi.org/10.1037/pspp0000078] [PMID: 26692356]

[4] Svaldi J, Zimmermann S, Naumann E. The impact of an implicit manipulation of self-esteem on body dissatisfaction. J Behav Ther Exp Psychiatry 2012; 43(1): 581-6.

[http://dx.doi.org/10.1016/j.jbtep.2011.08.003] [PMID: 21884668]

[5] Neighbors LA, Sobal J. Prevalence and magnitude of body weight and shape dissatisfaction among university students. Eat Behav 2007; 8(4): 429-39.

[http://dx.doi.org/10.1016/j.eatbeh.2007.03.003] [PMID: 17950931]

[6] Rudd NA, Lennon SJ. Body image: Linking aesthetics and social psychology of appearance. Cloth Text Res J 2001; 19(3): 120-33. [http://dx.doi.org/10.1177/0887302X0101900303]

[7] Ridgway JL, Clayton RB. Instagram unfiltered: Exploring associations of body image satisfaction, Instagram\# selfie posting, and negative romantic relationship outcomes. Cyberpsychol Behav Soc Netw 2016; 19(1): $2-7$.

[http://dx.doi.org/10.1089/cyber.2015.0433] [PMID: 26779659]

[8] Biolcati R, Passini S. Narcissism and self-esteem: Different motivations for selfie posting behaviors 2018 .

[http://dx.doi.org/10.1080/23311908.2018.1437012]

[9] March E, McBean T. New evidence shows self-esteem moderates the relationship between narcissism and selfies. Pers and Ind Diff 2018; 130: 107-11.

[http://dx.doi.org/10.1016/j.paid.2018.03.053]

[10] Sorokowski P, Sorokowska A, Oleszkiewicz A, et al. Selfie posting behaviors are associated with narcissism among men. Pers Individ Dif 2015; 85: 123-7.

[http://dx.doi.org/10.1016/j.paid.2015.05.004]

[11] Perrin A. Social media usage 2015.http://www.pewinternet.org/2015/10/08/2015/Social-Networking -Usage-2005-2015/

[12] Katz JE, Crocker ET. Selfies| selfies and photo messaging as visual conversation: Reports from the United States, United Kingdom and China. Int J Commun 2015; 9: 12.http://ijoc.org

[13] Dhir A, Pallesen S, Torsheim T, Andreassen CS. Do age and gender differences exist in selfie-related behaviours? Comput Human Behav 2016; 63: 549-55

[http://dx.doi.org/10.1016/j.chb.2016.05.053]

[14] Rutledge CM, Gillmor KL, Gillen MM. Does this profile picture make me look fat? Facebook and body image in college students. Psychol Pop Media Cult 2013; 2(4): 251.

[http://dx.doi.org/10.1037/ppm0000011]

[15] Oberst U, Renau V, Chamarro A, Carbonell X. Gender stereotypes in Facebook profiles: Are women more female online? Comput Human Behav 2016; 60: 559-64

[http://dx.doi.org/10.1016/j.chb.2016.02.085]

[16] Bergman SM, Fearrington ME, Davenport SW, Bergman JZ. Millennials, narcissism, and social networking: What narcissists do on social networking sites and why. Pers Individ Dif 2011; 50(5): 706-11. [http://dx.doi.org/10.1016/j.paid.2010.12.022] 
[17] Stănculescu E. Online self-presentation from the cyberpsychology perspective, in Proceedings of the $7^{\text {th }}$ international Scientific Conference eLearning and Software for Education «(eLSE) 2011; Bucharest: Universitatea Nationala de Aparare Carol I. 2011; 155-60.https://www.ceeol.com/search/article-detail?id=25801

[18] Diefenbach S, Christoforakos L. The selfie paradox: Nobody seems to like them yet everyone has reasons to take them. An exploration of psychological functions of selfies in self-presentation. Front Psychol 2017; 8: 7.

[http://dx.doi.org/10.3389/fpsyg.2017.00007] [PMID: 28144225]

[19] Suler J. From Self-Portraits to Selfies. Eur J Mark 2015; 12(2): 175-80.

[20] Pounders K, Kowalczyk CM, Stowers K. Insight into the motivation of selfie postings: Impression management and self-esteem. Eur J Mark 2016; 50(9/10): 1879-92.

[http://dx.doi.org/10.1108/EJM-07-2015-0502]

[21] Wagner CN, Aguirre Alfaro E, Bryant EM. The relationship between Instagram selfies and body image in young adult women. First Monday 2016; 21(9)

[http://dx.doi.org/10.5210/fm.v21i9.6390]

[22] Drydakis N. The effect of unemployment on self-reported health and mental health in Greece from 2008 to 2013: A longitudinal study before and during the financial crisis. Soc Sci Med 2015; 128: 43-51. [http://dx.doi.org/10.1016/j.socscimed.2014.12.025] [PMID: 25589031]

[23] Schoon I, Mortimer J. Youth and the great recession: Are values, achievement orientation and outlook to the future affected? Int $\mathrm{J}$ Psychol 2017; 52(1): 1-8. [http://dx.doi.org/10.1002/ijop.12400] [PMID: 27878820]

[24] Morf CC, Rhodewalt F. Unraveling the paradoxes of narcissism: A dynamic self-regulatory processing model. Psychol Inq 2001; 12: 177-96.

[http://dx.doi.org/10.1207/S15327965PLI1204_1]

[25] Nadkarni A, Hofmann SG. Why do people use Facebook? Pers Individ Dif 2012; 52(3): 243-9.

[http://dx.doi.org/10.1016/j.paid.2011.11.007] [PMID: 22544987]

[26] Mehdizadeh S. Self-presentation 2.0: Narcissism and self-esteem on Facebook. Cyberpsychol Behav Soc Netw 2010; 13(4): 357-64. [http://dx.doi.org/10.1089/cyber.2009.0257] [PMID: 20712493]

[27] Błachnio A, Przepiorka A, Rudnicka P. Narcissism and self-esteem as predictors of dimensions of Facebook use. Pers Individ Dif 2016; 90: 296-301.

[http://dx.doi.org/10.1016/j.paid.2015.11.018]

[28] Perloff RM. Social media effects on young women's body image concerns: Theoretical perspectives and an agenda for research. Sex Roles 2014; 71(11-12): 363-77.

[http://dx.doi.org/10.1007/s11199-014-0384-6]

[29] Robins RW, Tracy JL, Trzesniewski K, Potter J, Gosling SD. Personality correlates of self-esteem. J Res Pers 2001; 35(4): 463-82. [http://dx.doi.org/10.1006/jrpe.2001.2324]

[30] Mruk C. Self-Esteem: research, theory and practice. London: Free Association Books 1999

[31] Wang Y, Wang X, Liu H, Xie X, Wang P, Lei L. Selfie posting and self-esteem among young adult women: A mediation model of positive feedback and body satisfaction. J Health Psychol 2018; $\cdots 1359105318787624$

[http://dx.doi.org/10.1177/1359105318787624] [PMID: 30003803]

[32] Valkenburg PM, Peter J. Preadolescents' and adolescents' online communication and their closeness to friends. Dev Psychol 2007; 43(2): 267-77.

[http://dx.doi.org/10.1037/0012-1649.43.2.267] [PMID: 17352538]

[33] Zywica J, Danowski J. The faces of Facebookers: Investigating social enhancement and social compensation hypotheses; Predicting Facebook $^{\mathrm{TM}}$ and offline popularity from sociability and self-esteem, and mapping the meanings of popularity with semantic networks. J
Comput Mediat Commun 2008; 14(1): 1-34.

[http://dx.doi.org/10.1111/j.1083-6101.2008.01429.x]

[34] Biolcati R, Mancini G. Club drugs and rave parties: A Pilot Study on Synthetic Drug Consumption Styles in a Sample of Young Italian Ravers 2018.

[http://dx.doi.org/10.2174/1874944501811010474]

[35] Rosenberg M. Rosenberg self-esteem scale (RSE). Acceptance and commitment therapy Measures package 1965; 61: 52-61.http://ueb.ro/psihologie/docs/Psihologie_pozitiva_teste_si_scale .pdf\#page $=61$

[36] Orbach I, Mikulincer M. The body investment scale: Construction and validation of a body experience scale 1998 .

[http://dx.doi.org/10.1037/1040-3590.10.4.415]

[37] Skues JL, Williams B, Wise L. The effects of personality traits, selfesteem, loneliness, and narcissism on facebook use among university students. Comput Human Behav 2012; 28: 2414-9.

[http://dx.doi.org/10.1016/j.chb.2012.07.012]

[38] Sorokowska A, Oleszkiewicz A, Frackowiak T, et al. Selfies and personality: Who posts self-portrait photographs? Pers Individ Dif 2016; 90: 119-23.

[http://dx.doi.org/10.1016/j.paid.2015.10.037]

[39] Krämer NC, Winter S. Impression management 2.0: the relationship of self-esteem, extraversion, self-efficacy, and self-presentation within social networking sites. J Media Psychol 2008; 20(3): 106-16. [http://dx.doi.org/10.1027/1864-1105.20.3.106]

[40] Valkenburg PM, Peter J. Online communication among adolescents: An integrated model of its attraction, opportunities, and risks. J Adolesc Health 2011; 48(2): 121-7.

[http://dx.doi.org/10.1016/j.jadohealth.2010.08.020] [PMID: 2125 7109]

[41] Biolcati R, Ghigi R, Mameli C, et al. What can I do with my body? Boys and girls facing body dissatisfaction. Int J Adolesc Youth 2017; 22(3): 283-95.

[http://dx.doi.org/10.1080/02673843.2016.1167748]

[42] Furnham A, Badmin N, Sneade I. Body image dissatisfaction: Gender differences in eating attitudes, self-esteem, and reasons for exercise. J Psychol 2002; 136(6): 581-96.

[http://dx.doi.org/10.1080/00223980209604820] [PMID: 12523447]

[43] Porch T. Society, culture, and the selfie: Analysis of the impact of the selfie practice on women's body image. Atlanta: Emory University 2015.

[44] Woodruff S, Santarossa S, Lacasse J. Posting\# selfie on Instagram: What are people talking about? Soc Media Soc 2018; 7(1): 4-14.

[45] Tice DM. Self-concept change and self-presentation: The looking glass self is also a magnifying glass. J Pers Soc Psychol 1992; 63(3): 435-51.

[http://dx.doi.org/10.1037/0022-3514.63.3.435] [PMID: 1403623]

[46] Steiger AE, Allemand M, Robins RW, Fend HA. Low and decreasing self-esteem during adolescence predict adult depression two decades later. J Pers Soc Psychol 2014; 106(2): 325-38.

[http://dx.doi.org/10.1037/a0035133] [PMID: 24467425]

[47] Alblooshi A. Self-esteem levels \& selfies: The relationship between self-esteem levels and the number of selfies people take, post, and the uses and gratifications of taking and posting selfies (Unpublished master's thesis). Murfreesboro, TN: Middle Tennessee State University 2015.http://jewlscholar.mtsu.edu/handle/mtsu/4760

[48] Liu D, Baumeister RF. Social networking online and personality of self-worth: A meta-analysis. J Res Pers 2016; 64: 79-89. [http://dx.doi.org/10.1016/j.jrp.2016.06.024]

[49] Gonzales AL, Hancock JT. Mirror, mirror on my Facebook wall: Effects of exposure to Facebook on self-esteem. Cyberpsychol Behav Soc Netw 2011; 14(1-2): 79-83.

[http://dx.doi.org/10.1089/cyber.2009.0411] [PMID: 21329447]

[50] Charoensukmongkol P. Exploring personal characteristics associated with selfie-liking. Cyberpsychology (Brno) 2016; 10(2) [http://dx.doi.org/10.5817/CP2016-2-7]

\section{(C) 2019 Roberta Biolcati.}

This is an open access article distributed under the terms of the Creative Commons Attribution 4.0 International Public License (CC-BY 4.0), a copy of which is available at: https://creativecommons.org/licenses/by/4.0/legalcode. This license permits unrestricted use, distribution, and reproduction in any medium, provided the original author and source are credited. 